\title{
A Stereolithographic Model-Based Dense Body Plan Generation Method to Construct a Ship Hydrodynamic Coefficients Database
}

\author{
Qianfeng Jing, Helong Shen and Yong Yin * \\ Key Lab. Of Marine Simulation and Control, Department of Navigation, Dalian Maritime University, \\ Dalian 116026, China; jqf64078@gmail.com (Q.J.); shenhelong@126.com (H.S.) \\ * Correspondence: bushyin@dlmu.edu.cn
}

Received: 28 February 2020; Accepted: 18 March 2020; Published: 21 March 2020

\begin{abstract}
A ship's body plan is a vital data resource of ship hydrodynamics analysis, especially for time-domain simulations. Motivated by 3D printing technology, a novel dense body plan generation method is developed in this study. The slicing algorithm is adopted to generate dense $2 \mathrm{D}$ body plans from ship stereolithographic models. The dense body plan can be produced automatically under arbitrary rotational angles and slices. Moreover, a section redistribution algorithm is integrated to eliminate the non-uniform distribution features in sliced data inherited from the stereolithographic models. The benchmark ship models are selected to validate the accuracy of the method. The hull volumes of three ship models are calculated based on the produced data. The calculated results show satisfactory agreement with the published values. Furthermore, the estimation formulas of wetted surface area (WSA) are reviewed and utilized for validation. The calculated WSAs by slice integration turn out to be adaptive and accurate. The time costs of different slices are provided to illustrate the computational efficiency. A ship hydrodynamic coefficients database is constructed based on a 2D strip method and the produced data. The proposed method aims to improve the generation process of the body plan, which could meet the accuracy requirements of the strip method. As a result, hydrodynamic coefficients utilized in time-domain simulations could be obtained smoothly from the database.
\end{abstract}

Keywords: dense body plan; 3D printing; stereolithographic model; hydrodynamic coefficients database; time-domain simulation

\section{Introduction}

The maneuvering behaviors of a ship in an actual ocean environment are complicated. Large roll and pitch angles may occur in adverse weather conditions [1]. Ships may even sink in extremely rough seas [2]. However, simulation-based approaches provide a flexible and resource-saving way to predict and analyze ship performance in the ocean environment [3]. Therefore, numerical simulations are applied to enhance the safety of navigation in the maritime sector [4]. In addition, the simulation of ship motion in waves is a key component of marine simulators [5]. Precise motion prediction would ensure the physical reality of the simulators. Moreover, fast simulations of trajectory and motion status allow deck officers to judge whether the maneuvering actions have the correct tendency or indicate the need for corrections [6]. The simulation of ship motions could also contribute to the development of the model's predictive control algorithm [7]. Since the wave disturbance is the most dangerous effect in navigation, many investigations have focused on simulating ship maneuvering behaviors in waves [8-11]. The pioneering work in this field was undertaken by Cummins [12] and Ogilvie [13]. The impulse response function (IRF) is introduced and developed in their work, and the memory effect 
in the time-domain is estimated by linear convolution. Accordingly, the simulation of ship motion in waves has become a research frontier of ship hydrodynamics in recent years and has also attracted great attention in the International Towing Tank Conference (ITTC) [14]. The mean second-order wave loads in ship motion simulation under regular waves are obtained by a Rankine panel method in some recent studies [15-17]. Nevertheless, numerous works have reported the simulation analysis of ship maneuvering in waves based on 2D and 2.5D strip theory [18-24]. The fluid potential is obtained based on a ship lines plan in both 2D and 2.5D theory. Besides, the strip-based formulation has been found to be numerically stable and robust, which are critical aspects when performing long-term maneuvering simulations. The accuracy of hydrodynamic coefficients based on strip theory was compared with three-dimensional panel methods, and the results indicated that the strip theory is a practical and effective method in time-domain simulations $[25,26]$. Furthermore, a frequency-domain coefficients database could be conveniently constructed by either panel methods $[27,28]$ or strip methods [20]. The wave-induced forces/moments could be calculated based on the database, which is particularly computationally efficient in ship maneuvering simulators [29].

Notably, the ship's body plan is the essential prerequisite for calculating wave load coefficients in strip theory. The number and accuracy of the ship hull sections will influence the accuracy of the coefficients undoubtedly. Generally, the ship's body plan is obtained from the digital lines plan with the help of computer-aided design (CAD) modeling tools, which is a very time-consuming task [30]. The number of sections in an original body plan is usually limited and is therefore not able to describe the ship geometry in detail. It is necessary to divide the ship into more than 60 stations to get the converge solution for high-speed ships, and a body plan with low quality may lead to lower calculation accuracy or convergence problems in strip methods [24]. However, limited literature has investigated the high-quality and automatic body plan generation method. Recently, 3D printing, also known as additive manufacturing, has been making waves across various industries due to its versatility, cost reduction capabilities, and sheer convenience. The research interest of this technology has spread into the field of marine engineering [31,32]. The stereolithographic model is widely used in $3 \mathrm{D}$ printing, which could accurately describe the geometry by using a large number of triangular facets. The stereolithographic model slicing technology from 3D printing has shown great applied potential in the field of hydrostatic analysis. Liu developed a slicing algorithm based on the stereolithographic model to improve the accuracy of the draft survey [33]. Shen employed a model slicing technique to improve the calculation accuracy of the shear force and bending moment [34].

Motivated by the works above, this article focuses on generating a high-quality body plan based on the stereolithographic model. The main objective is not only to ensure the quality of the body plan used for hydrodynamic calculations but to improve the computational efficiency in generating the body plan. Therefore, an automated, accurate, and fast body plan generation method is developed to fill the gaps in the literature. The slicing algorithm is adopted to create sections from the hull stereolithographic model. The dense body plans can be produced under arbitrary rotation angles and slices without any other special manual treatments. Additionally, a section redistribution algorithm is integrated to process the non-uniform features inherited from the stereolithographic model. The hull volumes and wetted surface areas are calculated based on the produced body plan for validation. The accuracy is verified by comparing the computed results with the published values. The computational costs of the slicing process under different numbers of slices are provided to illustrate the effectiveness of the present method. A hydrodynamic coefficients database is built based on the strip method and the produced body plan. The varying wave-induced forces/moments could be obtained based on interpolation from the database. Consequently, the present method could be smoothly integrated into the time-domain maneuvering simulation in waves with fair calculation performance. 


\section{Three-Dimensional Printing and Stereolithographic Model}

\subsection{Three-Dimensional Printing}

The most-commonly used 3D printing process (46\% as of 2018) is a material extrusion technique called fused deposition modeling (FDM) [35]. The FDM process builds a three-dimensional object from a CAD model by successively adding material layer by layer. The flowchart of a general FDM process is shown in Figure 1.

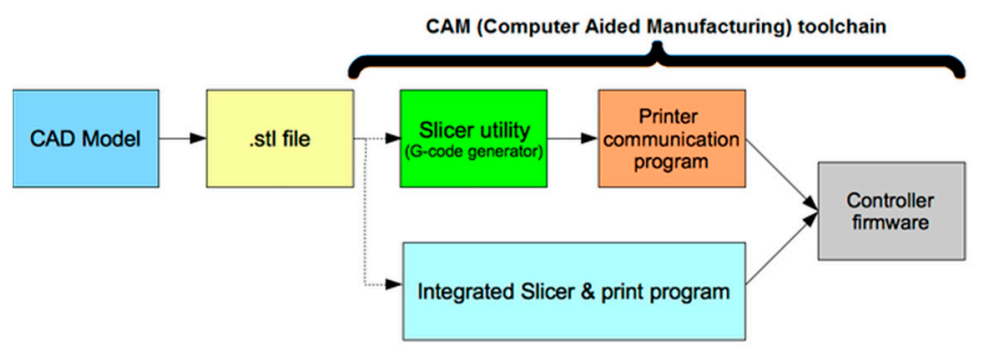

Figure 1. General fused deposition modeling (FDM) process.

The initial part of a 3D printing pipeline is to create digital prototypes using various CAD software. After establishing the digital 3D model, the integrated CAM software is utilized to generate the G-code file. Technically, G-code is a machine language used to drive the motion of motors. The main task of the CAM software is to slice the digital 3D model into layers and generate a G-code subsequently. The G-code will be transferred to the control module of a 3D printer after slicing. The 3D physical model of the KVLCC2 printed by the FDM process is shown in Figure 2.

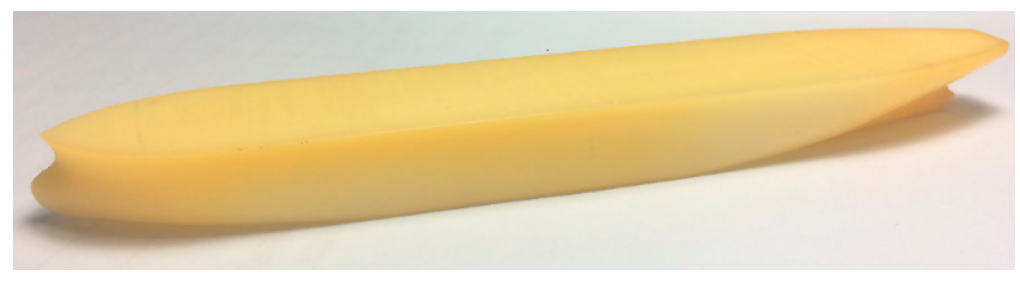

Figure 2. Printed model of KVLCC2 (FDM, scale 1:2000).

\subsection{Stereolithographic Model}

The prerequisite for producing any 3D printed part is a digital 3D model or a CAD file. The most widely used format of a digital 3D model in 3D printing is stereolithographic format due to its compact structure. The triangular facet is adopted to describe closed complex geometries in a stereolithographic model. The two format types of the model, the ASCII, and the binary are illustrated in Table 1. An ASCII stereolithography (STL) file begins with a solid name and concludes with the end solid name. It contains any number of triangles, where each $n$ or $v$ is a floating-point number. Since the ASCII STL files can become very large, a binary version of STL exists. A binary STL file has an 80-character header, where a four-byte little-endian unsigned integer indicating the number of triangular facets is present. Each triangle is described by twelve 32-bit floating-point numbers: three for the normal and then three for the $\mathrm{X} / \mathrm{Y} / \mathrm{Z}$ coordinate of each vertex. The file simply ends after the last triangle. 
Table 1. Stereolithographic model format.

\begin{tabular}{cc}
\hline ASCII & Binary \\
\hline Solid name & UINT8-header (80-character) \\
Facet normal $n_{i} n_{j} n_{k}$ & UINT32-number of triangles \\
Outer loop & For each triangle \\
Vertex $v 1_{x} v 1_{y} v 1_{z}$ & REAL 32-normal vector \\
Vertex $v 2_{x} v 2_{y} v 2_{z}$ & REAL32-vertex 1 \\
Vertex $v 3_{x} v 3_{y} v 3_{z}$ & REAL32-vertex 2 \\
End loop & REAL32-vertex 3 \\
End facet & UINT16-attribute byte count \\
End solid name & end \\
\hline
\end{tabular}

In this study, the benchmark models from the SIMMAN workshop are selected for investigation and validation [36]. The stereolithographic models and corresponding facets amount of the KVLCC2, KCS, and DTMB 5415 are shown in Figure 3.

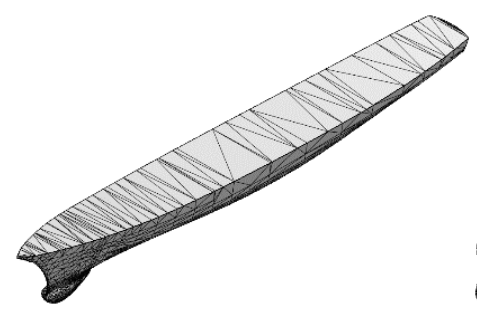

(a)

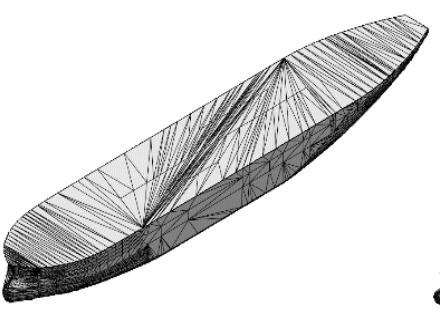

(b)

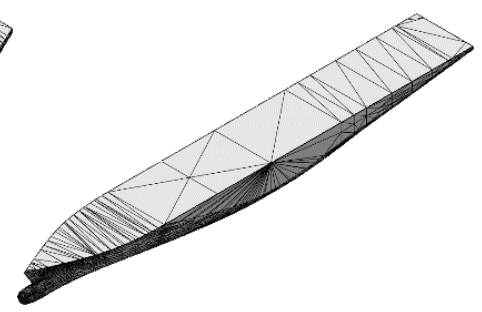

(c)

Figure 3. STL model of hulls (a): DTMB 5415, 5088 facets, (b): KVLCC2, 24,586 facets, (c): KCS, 8340 facets).

The vast number of facets describes the geometry of the hull precisely, as can be seen from the figures above. The facets distributed on the stereolithographic models are non-uniform. The smaller these facets are, the smoother the model will be, and the bigger the size of the model. The middle portion of a body plan generated from the original stereolithographic model is provided in Figure 4.

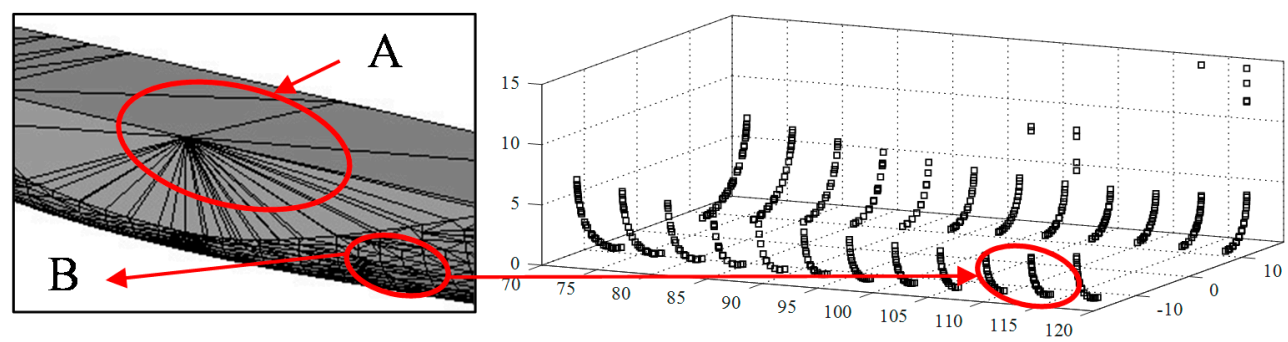

Figure 4. Non-uniform distribution of points (Left: midship area of KCS model; Right: sliced data).

The portion with small curvature is marked by $\mathrm{A}$, and the portion with large curvature is marked by $B$ in the left figure of Figure 4. An undeniable fact can be observed: the number of triangular facets in part A is less than part B. The large, flat plane in the stereolithographic models is easy to describe by a few large triangular facets, which could save storage space. In contrast, a curved plane needs a huge amount of small triangular facets due to the significant curvature. The middle sections of the generated body plan are provided in the right figure. Note that the body plan is produced by plane-triangular intersection processing; the points are scattered in the body plan due to the non-uniform distribution of triangular facets in the stereolithographic model. That is, the points of each section will accumulate in the portions with large curvature, as well as influencing the seakeeping calculation results negatively. 
Besides, the non-uniform distribution is a common feature in stereolithographic models, which can be observed in other models as shown in Figure 3.

A body plan (KCS) of 20 slices is selected to further illustrate the non-uniform feature inherited from the stereolithographic model. For each slice, the distance interval in space between two adjacent points is calculated. The statistical characteristics of these intervals are presented in Figure 5. The top figure in Figure 5 is the boxplot of the intervals. In each box, the central red line mark indicates the median, and the bottom and top edges of the blue box indicate the 25th and 75th percentiles, respectively. The whiskers extend to the most extreme data points not considered outliers, and the outliers are plotted individually using the red " + " symbol. In addition, the standard normal distribution is utilized to evaluate the non-uniform feature of the intervals. The probability density function $f(x)$ is calculated based on the mean value $\mu$ and the standard deviation $\sigma$ as in Equation (1), where the sample data $X$ refer to the intervals. The $f(x)$ of the intervals is provided in the bottom figure of Figure 5, where the dimension of the horizontal axis could be in centimeters or meters, depending on the stereolithographic model.

$$
X \sim N\left(\mu, \sigma^{2}\right), f(x)=\frac{1}{\sigma \sqrt{2 \pi}} \exp \left(-\frac{(x-\mu)^{2}}{2 \sigma^{2}}\right)
$$
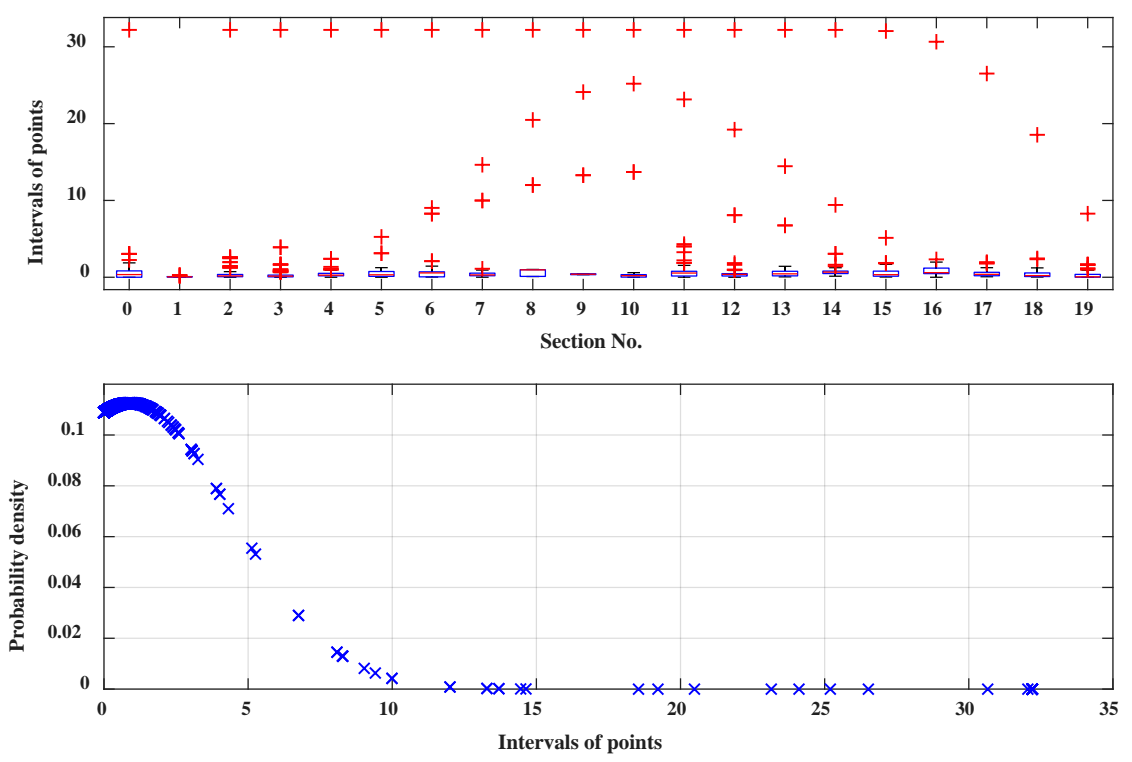

Figure 5. Intervals of points on sections (KCS; 20 slices).

The probability density indicates that the intervals below five make up the majority of all sections. Several outliers could be observed in each section from the boxplot. These outliers attribute to the non-uniform features in a triangular mesh. Therefore, these features cause similar non-uniformity in the produced body plan. The re-triangulation and optimization of the stereolithographic model will refine the mesh by rearranging the triangular facets. However, the non-uniformity features will remain [37-39]. Since the non-uniform features cannot be fully eliminated by optimization methods. A section redistribution algorithm is developed and integrated into the model slicing pipeline, which is explained in the model slicing algorithm.

\section{Model Slicing Pipeline}

The proposed method is developed based on the model slicing algorithm from the FDM process. Since the essential element of stereolithographic models is a triangular facet, the major task of the slicing operation is therefore converted into a space intersection problem. The intersection lines between 
a ship model and a moving cutting plane are computed from bow to stern in order to obtain the longitudinal offset data. Furthermore, similar operations can be performed from starboard to port side or each waterline to generate a transverse or vertical lines plan under a set of uniform or non-uniform cutting planes. The schematic diagram of the slicing process between a KCS stereolithographic model and a slice plane is shown in Figure 6.

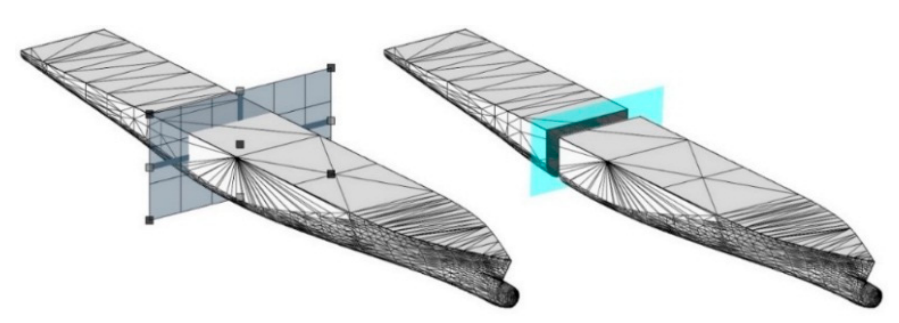

Figure 6. Cutting plane and hull stereolithographic model.

The set of cutting planes is prepared at the beginning of the slicing pipeline. The constant layer thickness along the slicing direction is adopted in uniform slicing and non-uniform slice planes and can be easily produced by a density distribution function or adaptive method based on surface curvature. Examples based on both uniform and non-uniform slicing are provided in Figure 7.

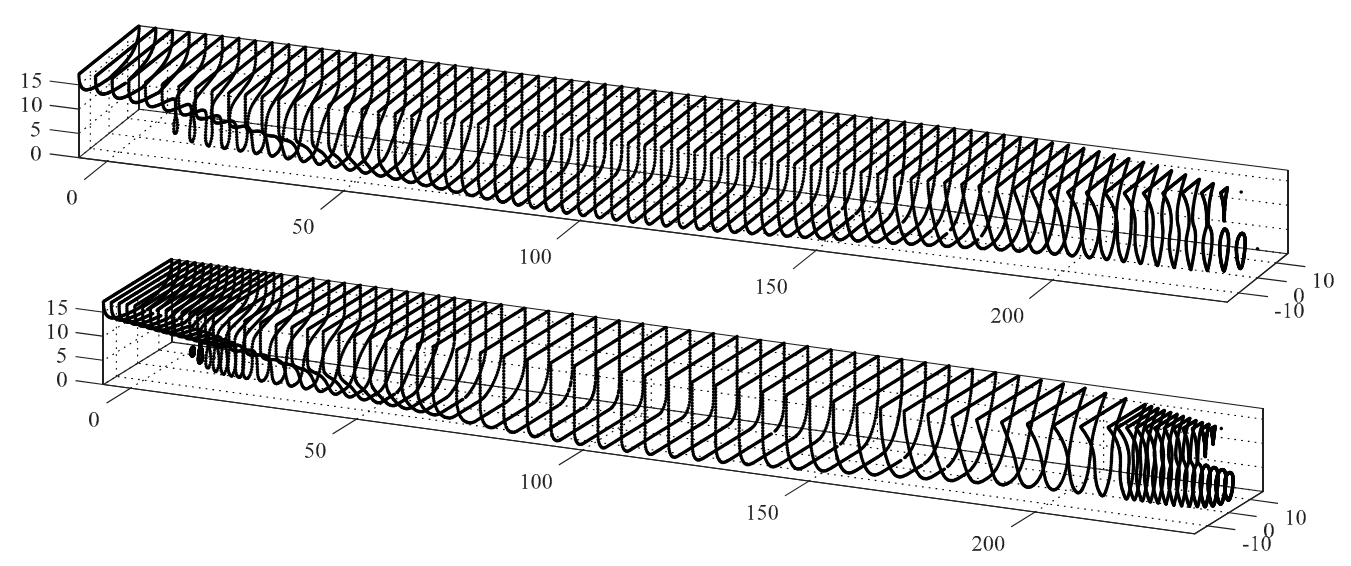

Figure 7. Uniform and non-uniform slicing (KCS, 70 slices, Top: uniform; Bottom: non-uniform).

In the time-domain strip method, the instantaneous wetted surface is calculated at each time step [19]. Particularly, the wetted surface varies during the six degrees of freedom (6-DOF) motions of a ship. The dense body plan under arbitrary roll and pitch angles can be conveniently produced by rotating the stereolithographic model. Based on the incident wave elevation around the ship, an instantaneous wetted surface could be integrated by limiting the body plan with the elevation in each longitudinal location. The slicing process of the rotated model is presented in Figure 8. Although the instantaneous free surface in the time-domain calculation is fully non-linear, an average steady water plane is adopted here to illustrate the effectiveness. The present method shows the applied potential in time-domain strip theory.

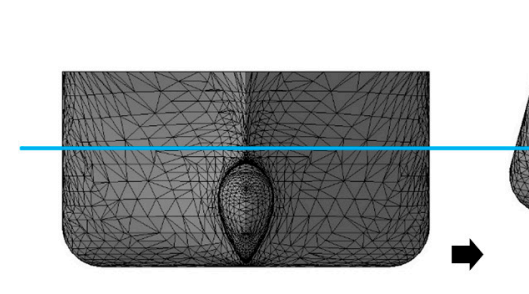

Raw

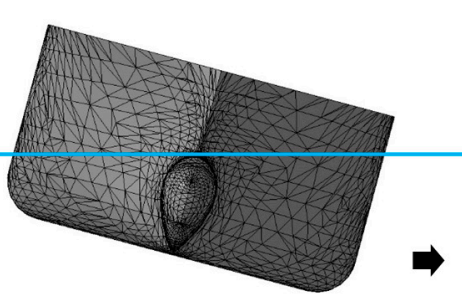

Rotated

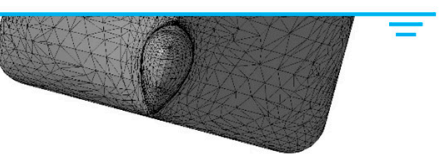

Limited

Figure 8. Rotated model slicing. 
In detail, the intersection lines between each triangular facet and the moving cutting plane need to be calculated in advance. The triangle-plane intersection problem can be considered as a specific case in which the two planes intersect. Figure 9 presents the intersection between a triangle facet and a cutting plane.

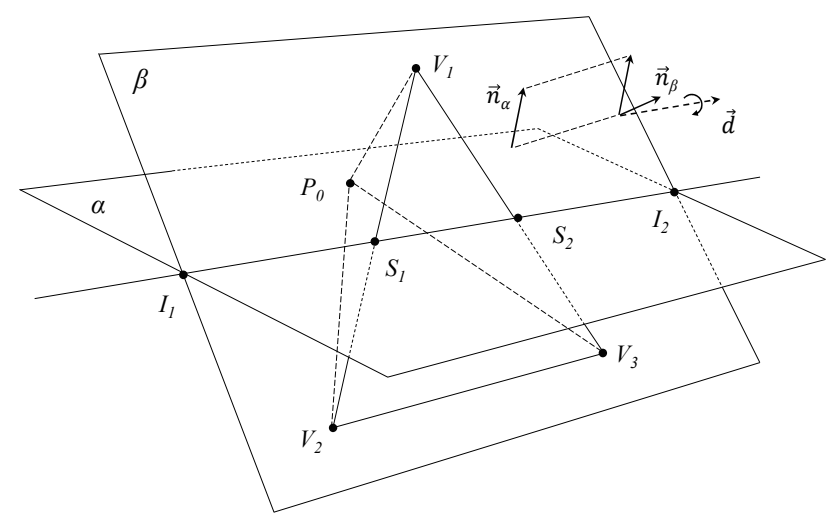

Figure 9. The intersection of a triangular facet with a cutting plane.

The plane $\alpha$ is the cutting plane with a normal $\vec{n}_{a}$. A triangular facet consists of three vertices $\left(V_{1}, V_{2}, V_{3}\right)$ coincident with the plane $\beta$. The corresponding normal of plane $\beta$ is $\vec{n}_{b}$. The vector $\overrightarrow{S_{1} S_{2}}$ is the intersection segment between the facet and the cutting plane. Besides, the vector $\vec{I}_{1} I_{2}$ is the intersection segment of the two planes. The situations of intersection can be determined by the geometric positional relationship between the three vertices and the plane. By selecting an arbitrary point $P_{0}$ on the plane $\alpha$, vectors are formed by the three vertices and the selected point. The dot products between the three vectors and the normal $\vec{n}_{a}$ will be utilized to determine the intersection as shown in Equation (2).

$$
\vec{n}_{\alpha} \cdot \vec{V}_{i} P_{0}=d_{i},(i=1,2,3)
$$

The facet intersects the cutting plane if the value of $d_{i}$ appears not only positive but negative. For the sake of generality, $V_{1}$ is above the cutting plane and $V_{2}$ and $V_{3}$ are below the cutting plane, as shown in Figure 6. The orientation of the intersection vector is determined by the cross product of two planes' normal, as in Equation (3).

$$
\vec{d}=\vec{n}_{\alpha} \times \vec{n}_{\beta}
$$

The intersection segment satisfies both the plane equation and the linear equation.

$$
\begin{gathered}
\vec{n}_{\alpha} \cdot \overrightarrow{S_{1} P_{0}}=0 \\
S_{1}=V_{1}+t \cdot\left(\overrightarrow{V_{1} V_{2}}\right)
\end{gathered}
$$

Substituting Equation (5) into Equation (4) gives

$$
\vec{n}_{\alpha} \cdot\left(V_{1}+t \cdot\left(\vec{V}_{1} V_{2}\right)-P_{0}\right)=\vec{n}_{\alpha} \cdot\left(V_{1}-P_{0}\right)+\vec{n}_{\alpha} \cdot t \cdot\left(V_{1}-V_{2}\right)=0
$$

The ratio $t$ in the linear equation is solved by Equation (7).

$$
t=\frac{-\vec{n}_{\alpha} \cdot\left(V_{1}-P_{0}\right)}{\vec{n}_{\alpha} \cdot\left(V_{1}-V_{2}\right)}
$$


Based on the dot products obtained by Equation (2), one of the endpoints of the intersection segment $S_{1}$ can be conveniently calculated using Equation (8), which saves the computational cost. In addition, the other endpoint $S_{2}$ can be derived from a similar approach.

$$
S_{1}=V_{1}+\frac{-\vec{n}_{\alpha} \cdot\left(V_{1}-P_{0}\right)}{\vec{n}_{\alpha} \cdot\left(V_{1}-V_{2}\right)}\left(V_{1}-V_{2}\right)=\frac{V_{1} \cdot d_{2}-V_{2} \cdot d_{1}}{d_{1}-d_{2}}
$$

Consequently, all intersection segments are obtained by sweeping all the facets of the hull stereolithographic model with all cutting planes. Note that the produced points on each slice are non-uniformly distributed, as described in Figure 5. Redundancy appears in the produced body plans, especially the portions where the curvature changes rapidly. Therefore, a redistribution algorithm (Algorithm 1) is implemented to obtain a uniform, low-redundancy section.

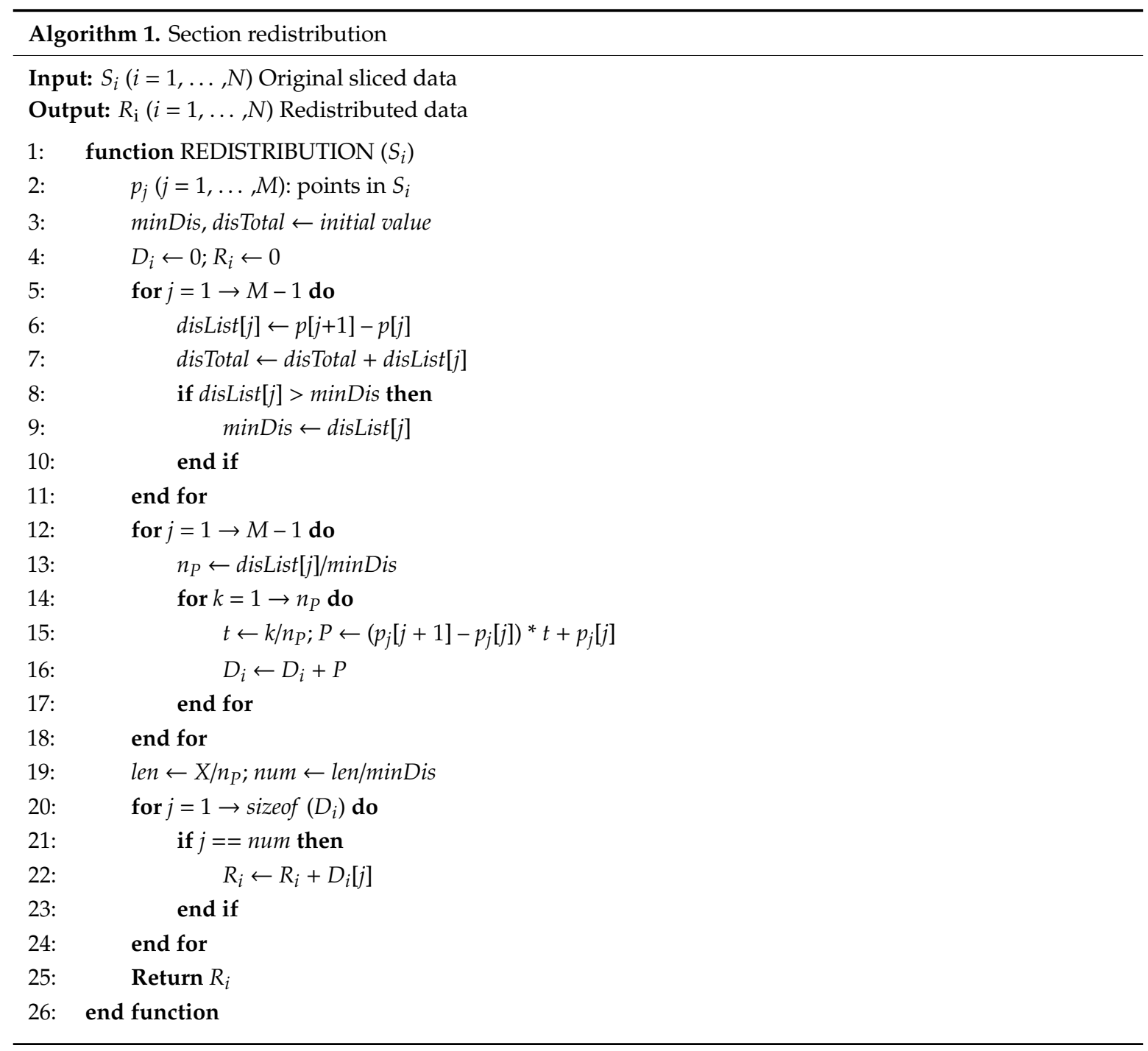

The developed algorithm improves the uniformity by redistributing the original sliced data. The algorithm consists of three basic steps. At first, the minimum value of the spacing of a slice is searched by sweeping the spacing of each two adjacent points. Then, the points are densified according to the minimum value by linear interpolation. Finally, uniform data under a specified amount of points are obtained by extracting the points from the densified data at a constant interval. The final dense body plan is generated based on the processes above. The pipeline of the stereolithographic model slicing is illustrated in Figure 10. 


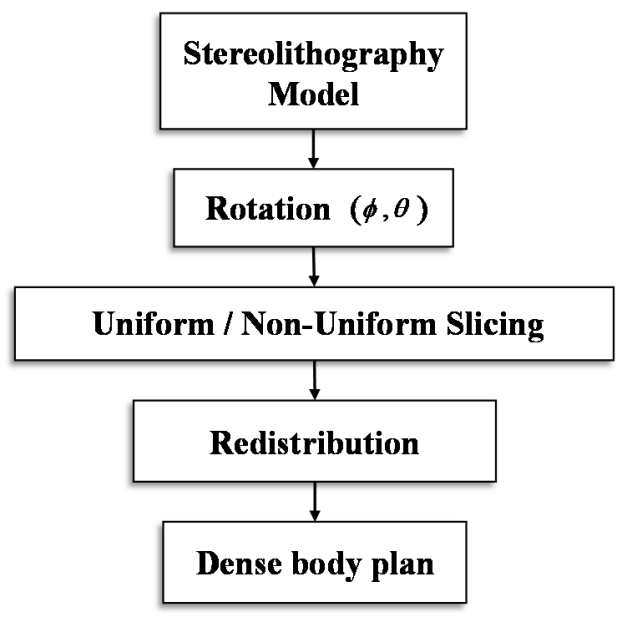

Figure 10. Stereolithographic model slicing pipeline.

\section{Dense Body Plan Results}

The produced body plans are shown in the following figures based on the present method. Initially, the data of the models under a rolling and pitching angle are presented in Figure 11. The sliced data along the transverse and vertical directions are provided in Figure 12. Besides, the body plans under different slices are given in Figure 13. Finally, the original sliced data are compared with the redistributed data in Figure 14.

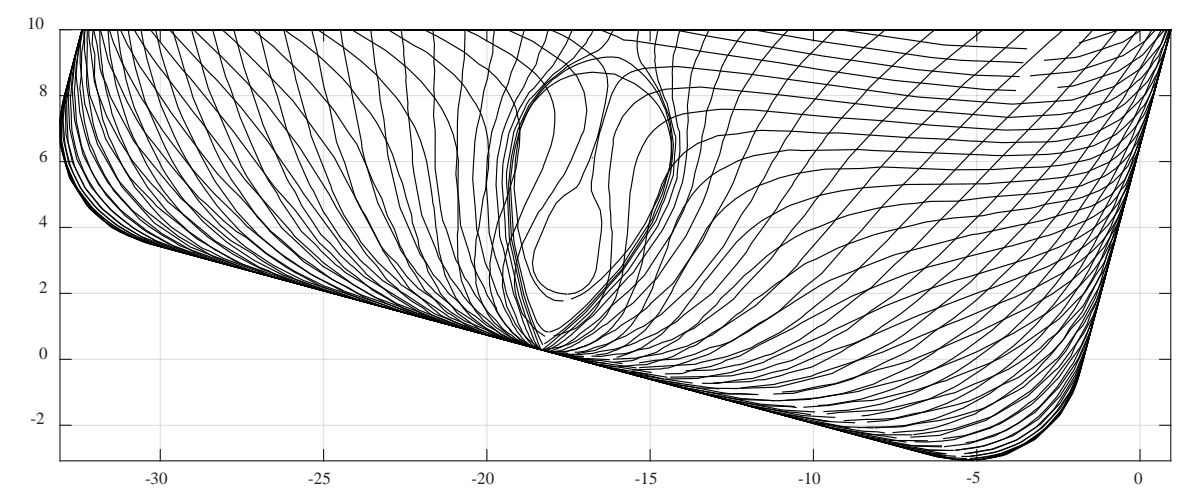

(a)

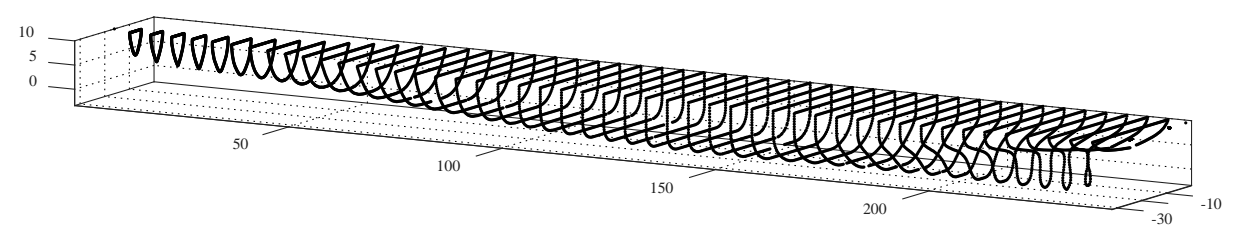

(b)

Figure 11. (a) Body plan under rolling (KCS, roll angle: $15^{\circ}, 70$ slices). (b) Body plan under pitching (KCS, pitch angle: $2^{\circ}, 50$ slices). 


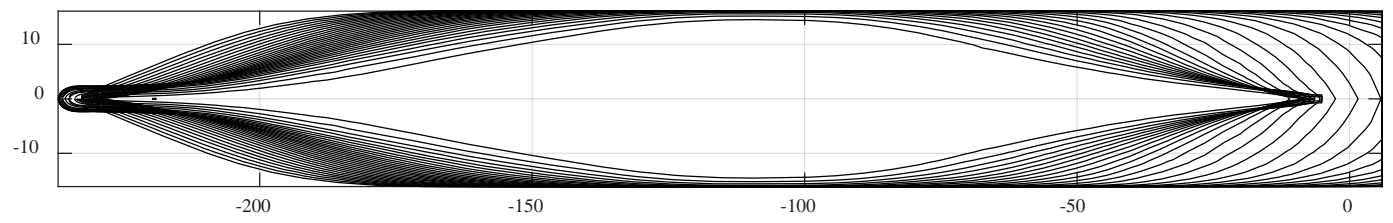

(a)

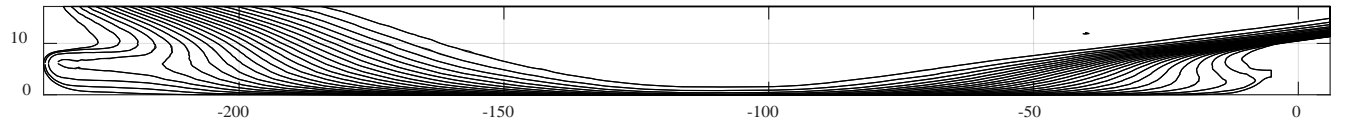

(b)

Figure 12. (a) Body plan of vertical slicing (KCS, 30 slices) (b) Body plan of transverse slicing (KCS, 50 slices).

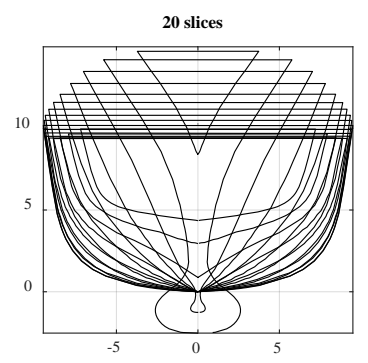

20 slices

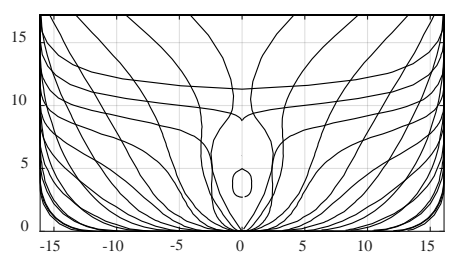

20 slices

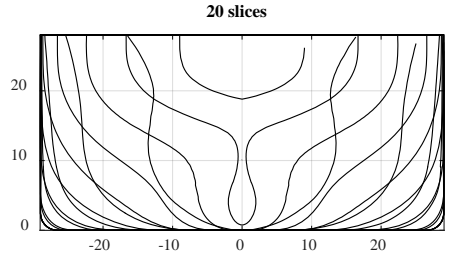

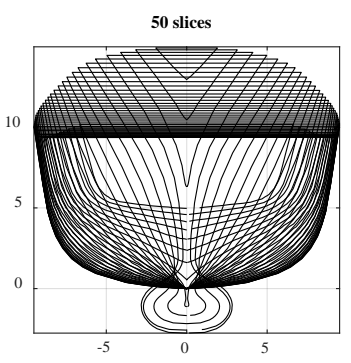

50 slices

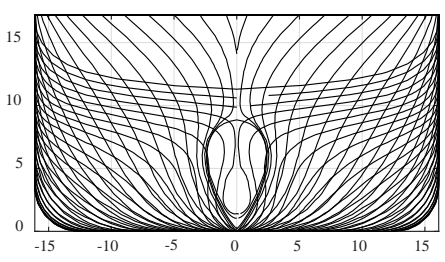

50 slices

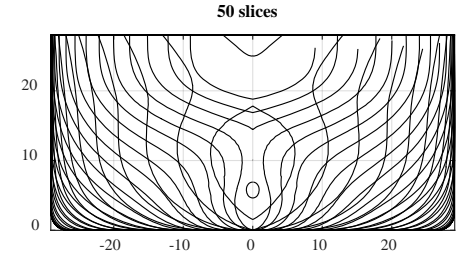

100 slices

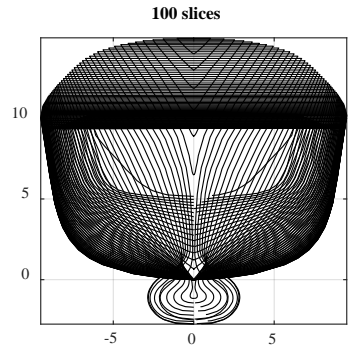

100 slices

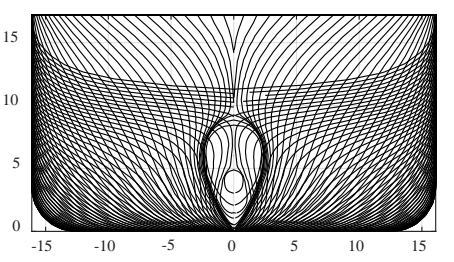

100 slices

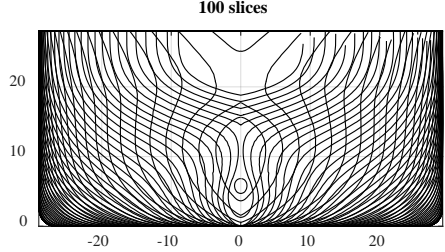

Figure 13. Body plan of different slice numbers. 

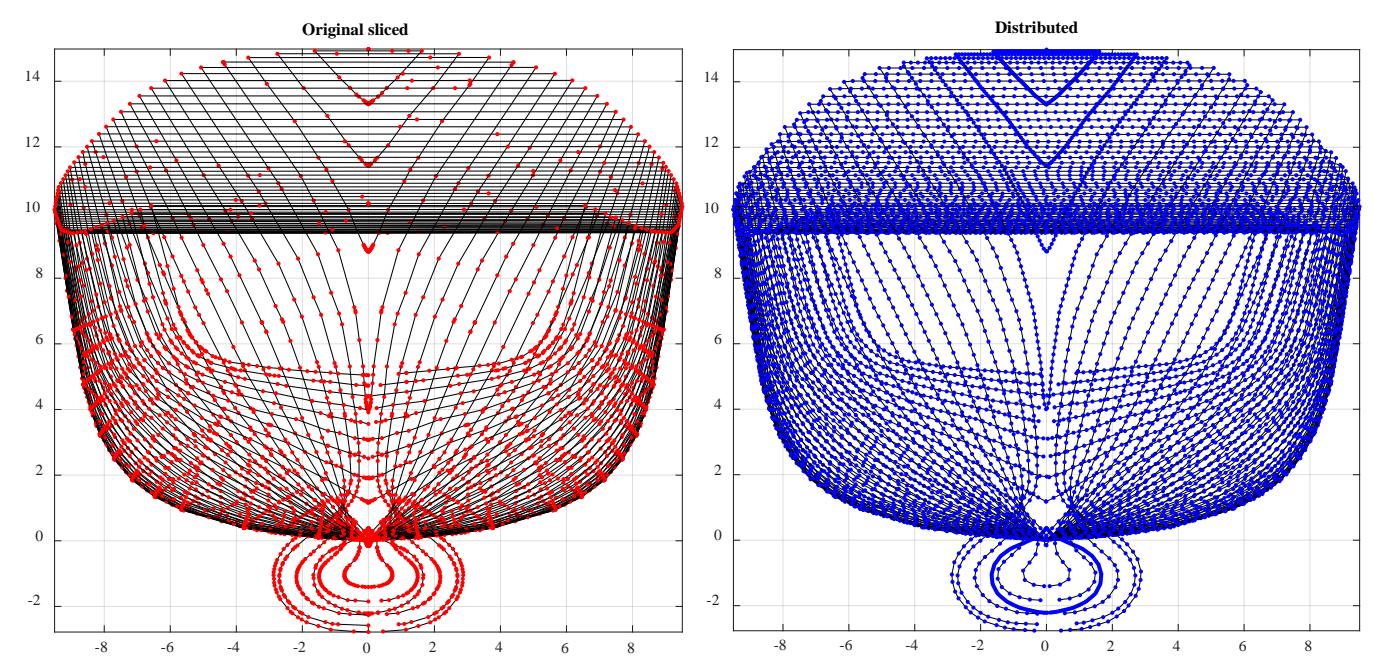

(a)
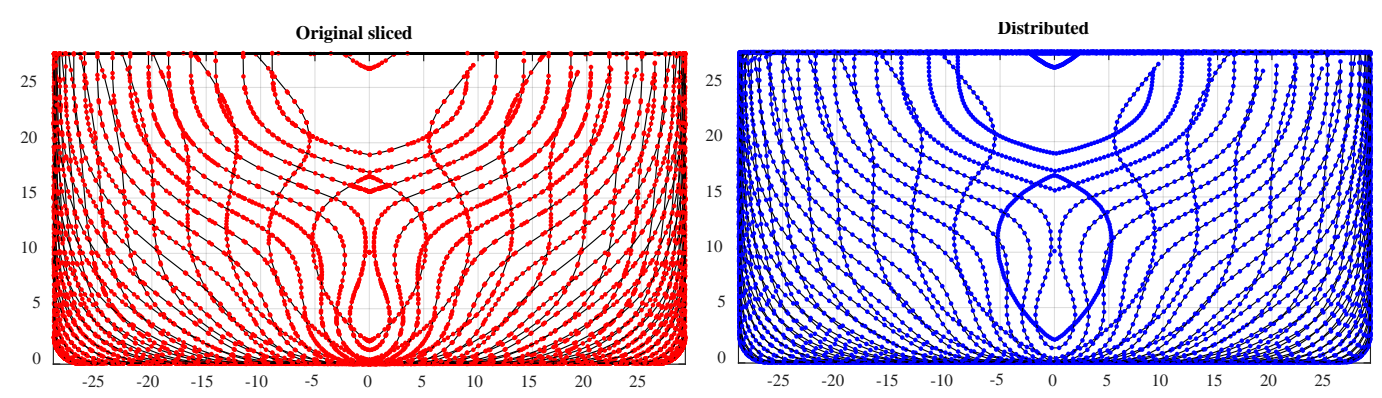

(b)
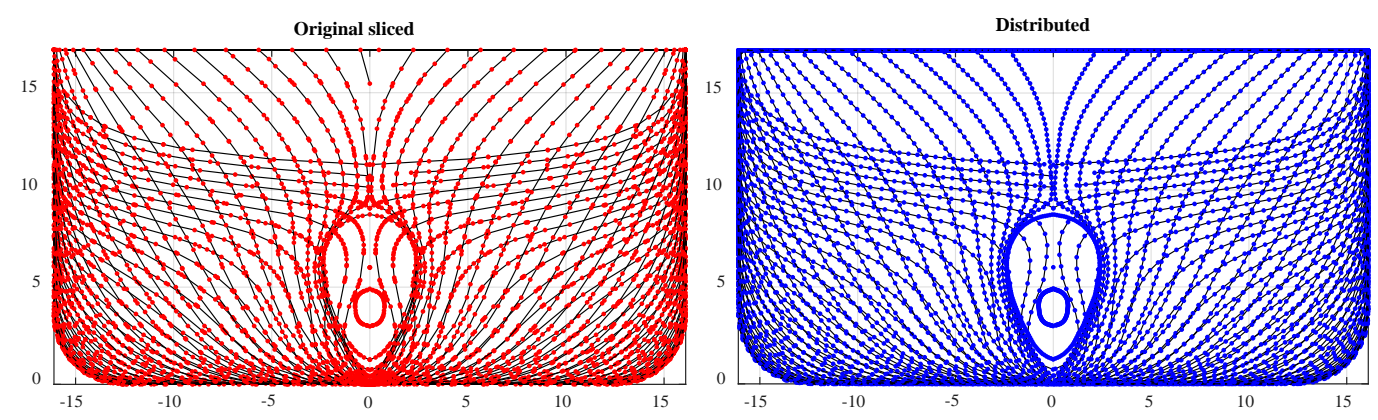

(c)

Figure 14. (a) Original sliced and redistributed data (DTMB 5415, 60 slices). (b) Original sliced and redistributed data (KCS, 60 slices). (c) Original sliced and redistributed data (KVLCC2, 60 slices).

\section{Validation of the Produced Body Plan}

Accuracy and efficiency are major factors to evaluate the present method. Two cases are provided to validate the accuracy of the produced data. The hull volume is widely used in the hydrostatic analysis. In addition, the WSA is often utilized for the estimation of the ship resistance in maneuvering simulations. Thus, the hull volumes and WSAs are calculated and compared with the published value. The published value of hull volumes and WSAs are given in Table 2. 
Table 2. The published value of DTMB5415, KCS and KVLCC2. WSA: wetted surface area.

\begin{tabular}{cccc}
\hline Ship & Facets $\mathbf{( N )}$ & Volume $\left(\mathbf{m}^{\mathbf{3}}\right)$ & WSA $\left(\mathbf{m}^{\mathbf{2}}\right)$ \\
\hline DTMB & 5088 & 8424.4 & 2972.6 \\
KCS & 8340 & 52030.0 & 9424.0 \\
KVLCC2 & 24586 & 312600.0 & 27194.0 \\
\hline
\end{tabular}

The hull volumes and WSAs can be integrated by produced body plan using Equation (9). $C_{i}$ and $A_{i}$ are the wetted perimeter length and area of each section, respectively.

$$
\begin{gathered}
W S A=\int_{L} C_{i}(x) \cdot d x \\
V=\int_{L} A_{i}(x) \cdot d x
\end{gathered}
$$

The calculated volumes are compared with the published value. The relative errors of the calculated results under different slice numbers are given in Table 3.

Table 3. Comparison of hull volumes.

\begin{tabular}{cccccc}
\hline Slice (N) & $\mathbf{2 0}$ & $\mathbf{5 0}$ & $\mathbf{1 0 0}$ & $\mathbf{2 0 0}$ & $\mathbf{5 0 0}$ \\
\hline DTMB $\left(\mathrm{m}^{3}\right)$ & 8347.34 & 8415.09 & 8425.93 & 8428.68 & 8429.22 \\
Error $(\%)$ & $0.915 \%$ & $0.111 \%$ & $0.018 \%$ & $0.051 \%$ & $0.057 \%$ \\
KCS $\left(\mathrm{m}^{3}\right)$ & 51909.53 & 52000.08 & 52021.66 & 52027.39 & 52029.59 \\
Error $(\%)$ & $0.232 \%$ & $0.058 \%$ & $0.016 \%$ & $0.005 \%$ & $0.001 \%$ \\
KVLCC $\left(\mathrm{m}^{3}\right)$ & 312244.97 & 312426.39 & 312505.17 & 312580.11 & 312591.34 \\
Error $(\%)$ & $0.114 \%$ & $0.056 \%$ & $0.030 \%$ & $0.006 \%$ & $0.003 \%$ \\
\hline
\end{tabular}

The maximum relative error of the calculated hull volumes is $0.915 \%$, which occurred in the DTMB 5415 model of 20 slices. The underwater geometry cannot be accurately described by only 20 slices due to the rapid change around the bulbous bow. In the case of 500 slices, the relative error decreases to $0.057 \%, 0.001 \%$, and $0.003 \%$. The relative errors are converged when the number of slices exceeds 200. Twelve regression-based approaches of WSA are reviewed and listed in Table 4 in order to validate the adaptability of the present method. The calculated WSAs the 20 and 200 slices of the body plans are selected to perform the comparison.

Table 4. The estimation methods of WSA.

\begin{tabular}{cccc}
\hline Number & Methods & Number & Methods \\
\hline No.1 & BSRA [40] & No.8 & Muragin \\
No.2 & Denny Mumford 1 [41] & No.9 & Krik (1880) \\
No.3 & Denny Mumford 2 [41] & No.10 & A.Normand (1870) [Mo] \\
No.4 & Froude 1 [41] & No.11 & S.Rosa (1961) \\
No.5 & Froude 2 [41] & No.12 & Holtrop [42] \\
No.6 & Tylor [41] & No.13 & 20 slices \\
No.7 & Bertram V. \& Schneekluth H. [43] & No.14 & 200 slices \\
\hline
\end{tabular}

Figure 15 illustrates the relative error of each WSA compared with the published value. The results show that the traditional methods have difficulties covering all the ship types. Note that the estimation methods (1-12) of WSA are mostly based on the regression analysis from a group of ships, or the approximate calculation using simplified ship geometries. Thus, the estimation approaches have limited accuracy, especially across the diversity of possible vessel types. However, the relative error of DTMB at 20 slices is greater than the other two ships, which demonstrates the limitation of a body plan at a small number of slices. The accuracy and adaptability based on the dense body plan of 200 slices are higher than all the estimation methods. Moreover, the present method could handle the ships equipped with special underwater appendages such as a bulbous bow. 


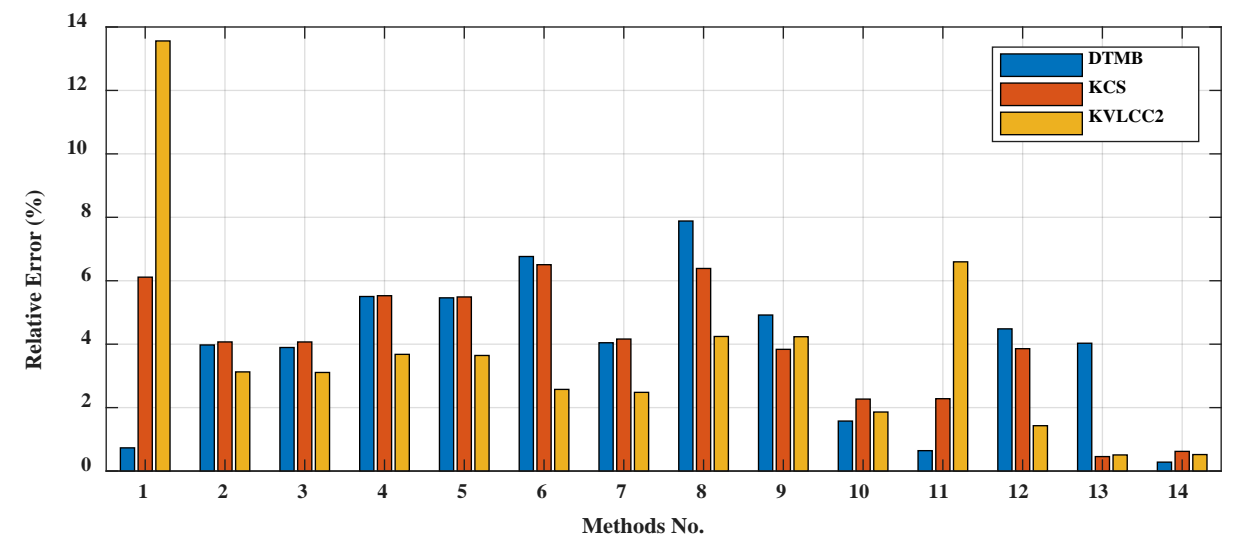

Figure 15. Comparison of WSAs.

The computational cost is another vital factor for evaluating this method. The number of facets varies according to the size of stereolithographic models, which leads to different time costs. Time costs of the three models are provided in Figure 16. The time cost is linearly increased from 20 slices to 200 slices in each model. For the KVLCC2 model, which has 24,586 facets, it takes $0.841 \mathrm{~s}$ to generate the 200 slice body plan. At present, the computation is based on CPU implementation and has not been processed in parallel. The experimental condition uses an Intel I7-8750H CPU $(2.20 \mathrm{GHz})$ and 16 G RAM.

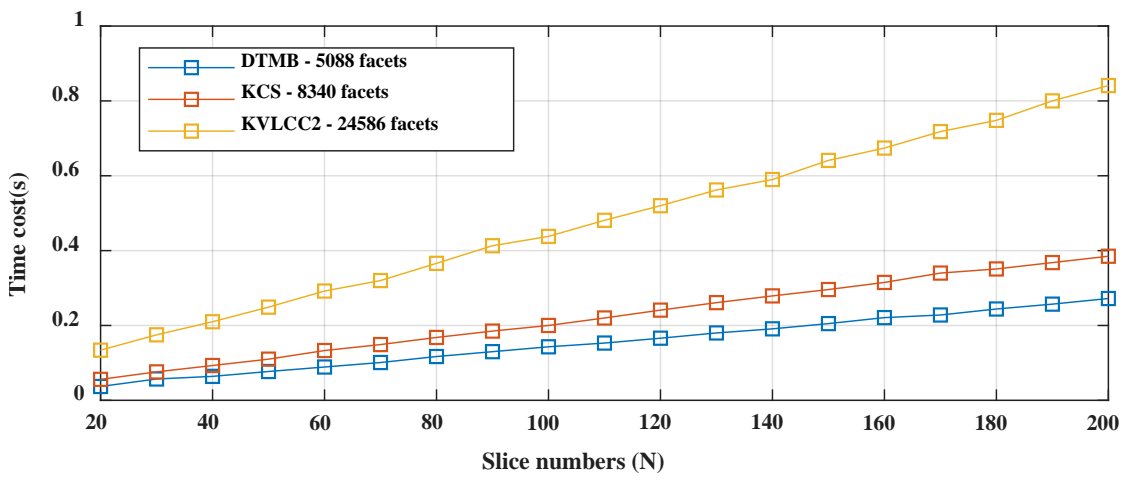

Figure 16. Computational costs.

\section{Hydrodynamic Coefficients Database}

The speed and heading of a ship change during maneuvering motion, which is not only caused by the operating engine and rudder but also by the environmental disturbances. However, ship motion in waves is commonly predicted at a constant forward speed, wave direction, and wave frequency in the seakeeping simulations. Both the forward speed and wave parameters vary in the actual sea. The different combination of the parameters leads to a different motion performance. Therefore, a hydrodynamic coefficients database is adopted to simulate the ship maneuvering motion in short-crested irregular waves. It is a powerful tool to handle the varying wave-induced forces/moments due to the changing ship speed and wave encounter angle. Such forces/moments could be practically superposed using coefficients of discrete frequency and phase based on the linear hypothesis. For instance, a unified model expanded from Fossen [9] is shown in Equation (10).

$$
\begin{gathered}
M \dot{v}=f_{H}+f_{\mathrm{P}}+f_{R}+f_{\text {wind }}+f_{\text {current }}+f_{\text {excitation }}+f_{\text {drift }} \\
f_{H}=-A(\infty) \dot{v}-B(\infty) v-\int_{0}^{t} K(t-\tau)\left[v(\tau)-U e_{1}\right] d \tau-C \eta+f_{N L-H u l l}(v)
\end{gathered}
$$

where $M$ is the mass matrix, and $H, P, R$ refer to the hull, propeller, and rudder according to the modular concept. The wind, current, excitation, and drift subscripts represent the wind, current, wave 
excitation forces/moments, and wave steady drift forces/moments. NL-Hull is the non-linear viscous forces/moments in maneuvering. Note that the IRF (K), the added mass (A), and the damping (B) are in a $6 \times 6$ matrix at each speed and wave direction. The convolution integral of IRFs captures the so-called fluid memory effects. Therefore, it is necessary to consider the varying IRFs, added mass, and damping during the time-domain simulation. These IRFs are pre-calculated offline based on the frequency-domain hydrodynamic coefficients using Equation (11).

$$
K(t)=\frac{2}{\pi} \int_{0}^{\infty} B(\omega) \cos (\omega t) d \omega
$$

By utilizing a database, the IRFs are interpolated by instant speed and wave encounter angle in the time-domain simulations. The first-order wave forces/moments in random seas can be easily computed based on a Response Amplitude Operator (RAO) database and 2D wave spectra. In addition, second-order wave load coefficients could be interpolated from a similar database. The databases are made as a function of ship speed, wave frequency and wave direction. For example, the steady wave-induced drift forces/moments could be obtained by Equation (12). Here, $C$ is the wave drift force coefficient at a specific combination of the ship speed $U$, the wave frequency $\omega_{k}$, and the wave encounter angle $\chi_{e}$. Besides, the symbol $T$ refers to the average wave period, $S_{\zeta \zeta}$ is the wave spectra, $\theta_{n}$ is the wave spreading angle, $H_{1 / 3}$ represents the wave significant height, and $F$ refers to the wave drift forces/moments.

$$
\begin{aligned}
\bar{C}\left(U, T, \chi_{e}\right) & =2 \sum_{\omega=0}^{K} \sum_{\theta=0}^{N} C\left(U, \omega_{k}, \chi_{e}\right) \cdot \frac{S_{\zeta \zeta}\left(\omega_{k}, \theta_{n}\right)}{H_{1 / 3}^{2}} \cdot \Delta \omega \cdot \Delta \theta \\
F_{X}\left(U, \chi_{e}\right) & =\rho \cdot g \cdot H_{1 / 3}^{2} \cdot L \cdot \bar{C}_{X}\left(U, \chi_{e}\right) \\
F_{Y}\left(U, \chi_{e}\right) & =\rho \cdot g \cdot H_{1 / 3}^{2} \cdot L \cdot \bar{C}_{Y}\left(U, \chi_{e}\right), \chi_{e}=\chi-\psi \\
F_{N}\left(U, \chi_{e}\right) & =\rho \cdot g \cdot H_{1 / 3}^{2} \cdot L^{2} \cdot \bar{C}_{N}\left(U, \chi_{e}\right)
\end{aligned}
$$

A ship hydrodynamic coefficients database is constructed in this study based on the produced dense body plan and strip method. The strip theory-based Kochin-function method (SKFM) is used to calculate the hydrodynamic coefficients. This method has been proved effective in maneuvering simulation in waves [20]. The generated dense body plan of a real bulk carrier is shown in Figure 17.

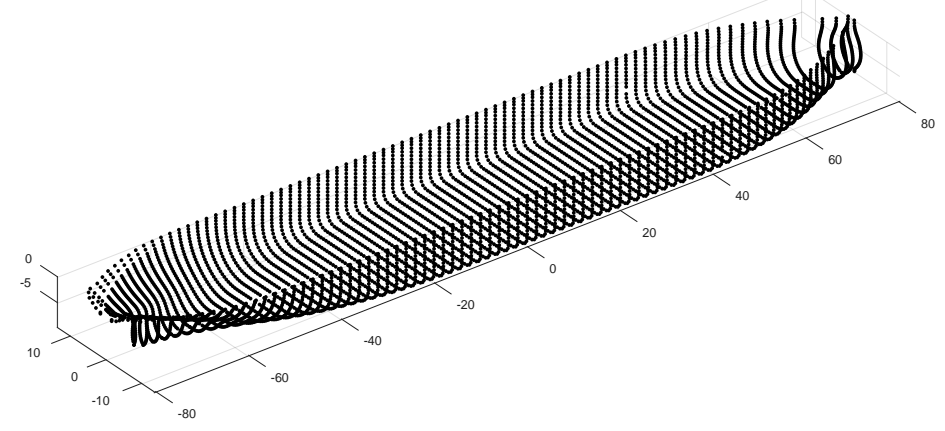

Figure 17. Dense body plan of a real bulk carrier (80 slices).

The hydrodynamic coefficients are organized by ship speed, wave frequency and wave encounter angle in the database. Part of the coefficients in the database are provided in Figures 18-21. The added mass, damping coefficients, motion RAOs and wave load RAOs are matrix values in the database. The ship speed varies from 0 to 12 knots, and the wave encounter angle varies from $0^{\circ}$ to $180^{\circ}$. The frequency interval is $0-0.3 \mathrm{~Hz}$. 


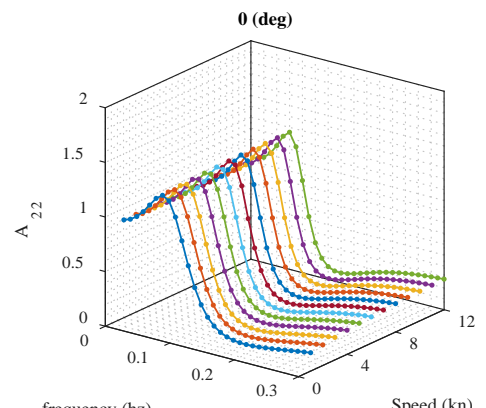

frequency (hz)

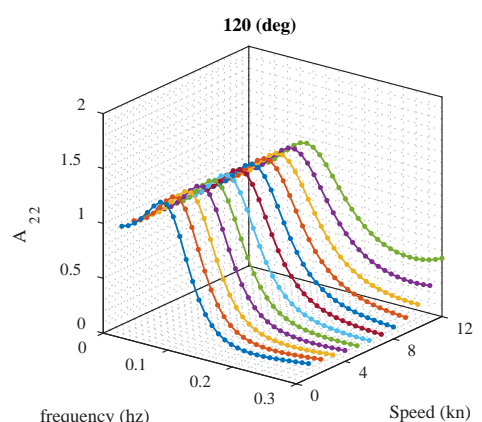

frequency (hz)

Speed (kn)

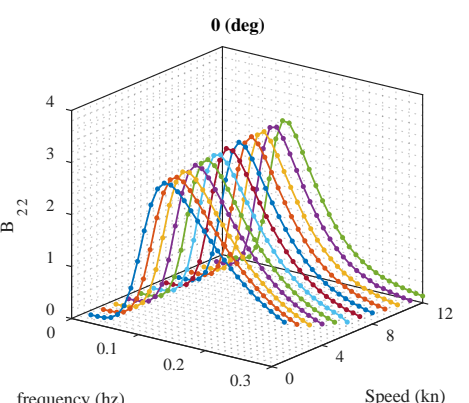

frequency (hz)

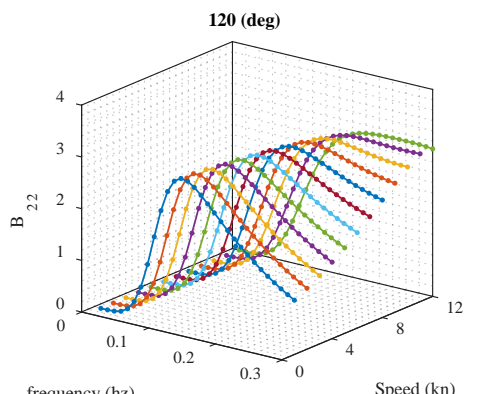

frequency (hz)

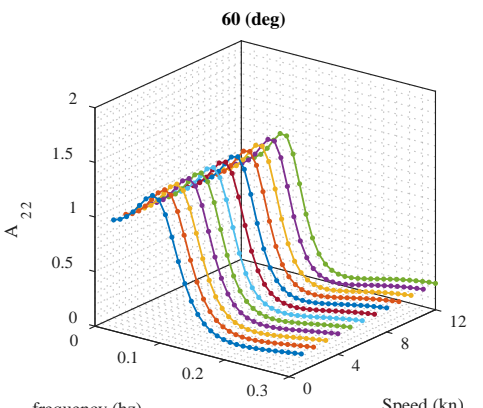

frequency (hz)

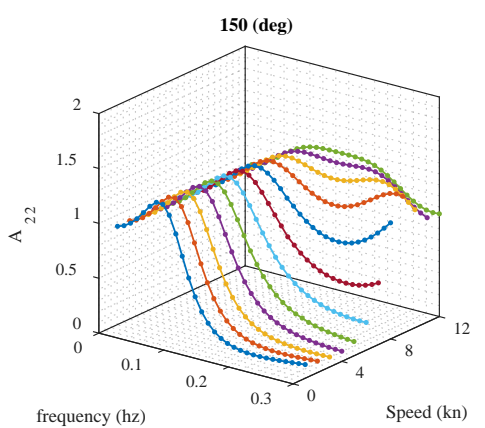

Figure 18. Added mass $\left(\mathrm{A}_{22}\right)$.

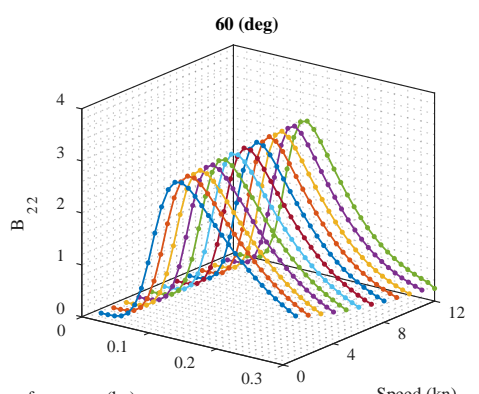

frequency (hz)

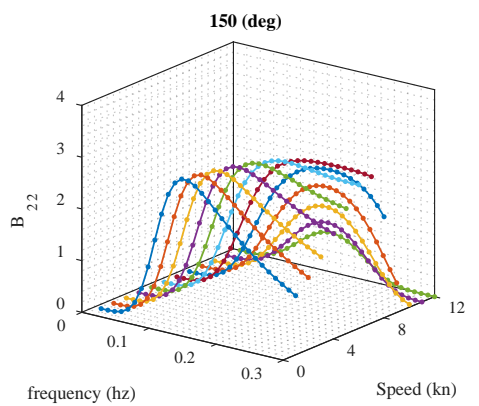

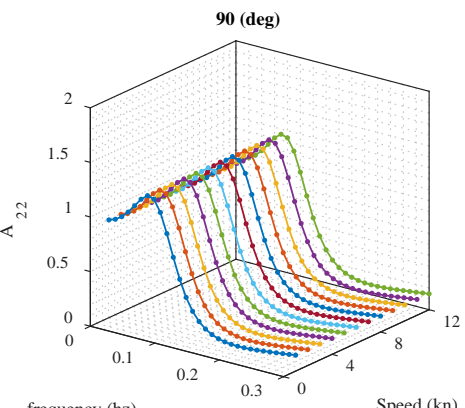

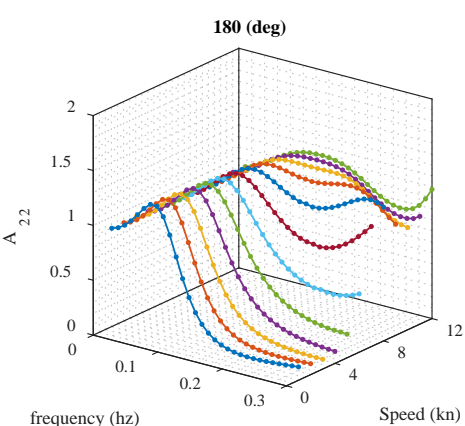

Speed (kn)
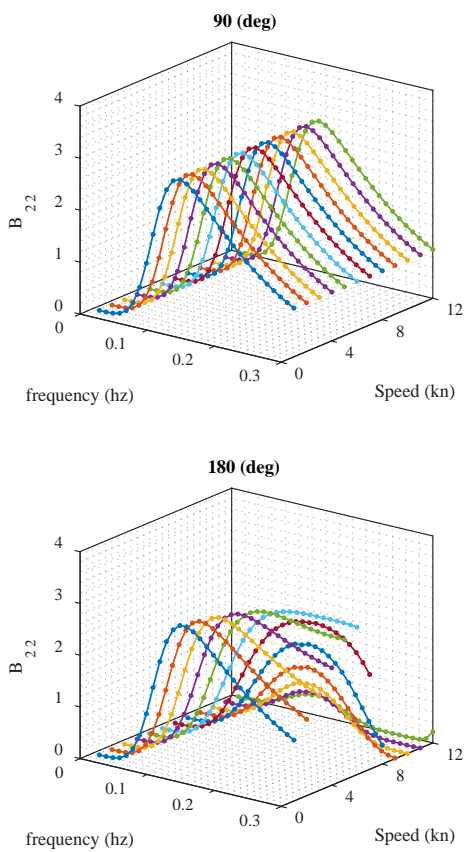

Figure 19. Damping coefficient $\left(B_{22}\right)$. 

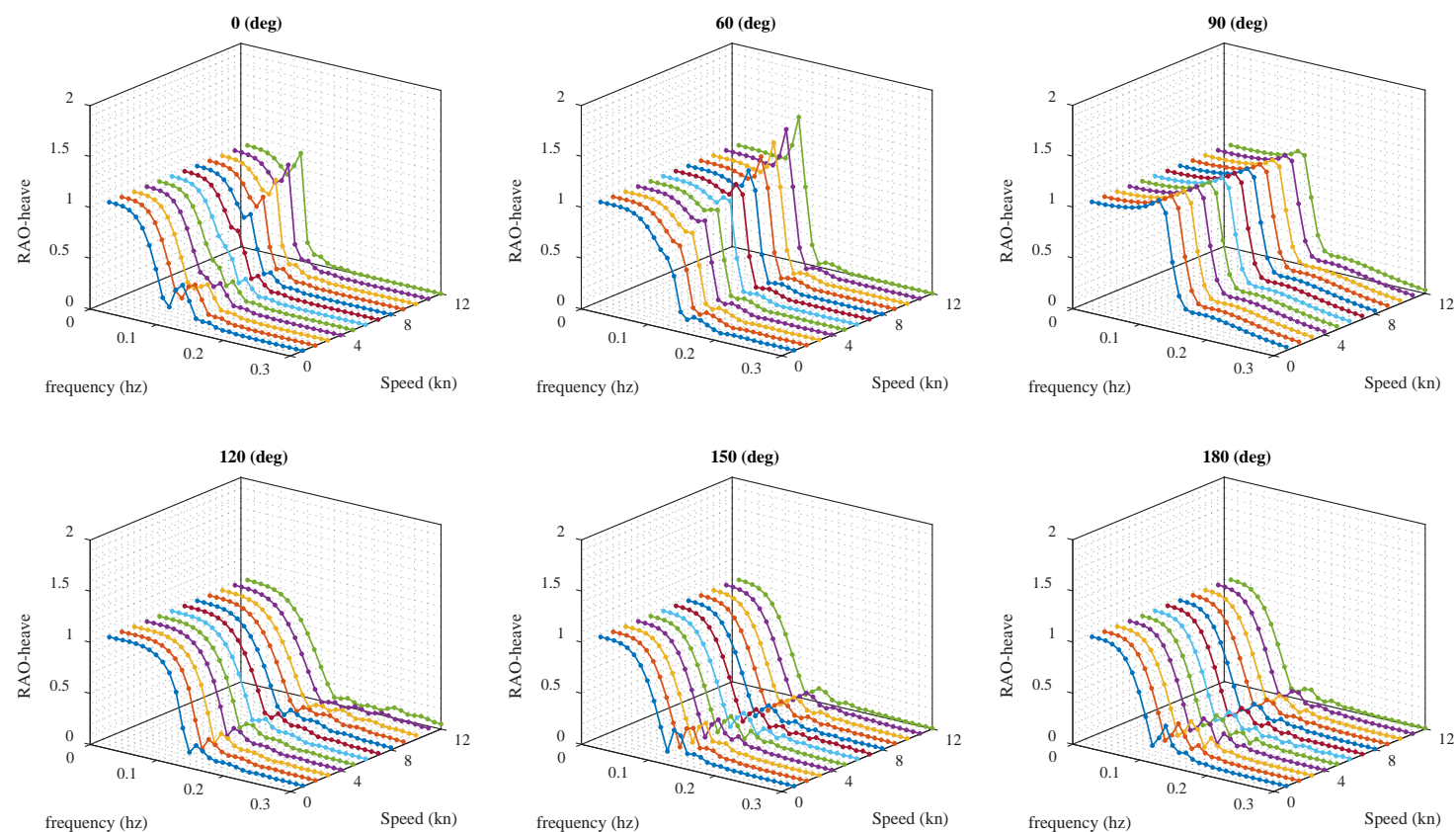

Figure 20. Motion RAO (heave).
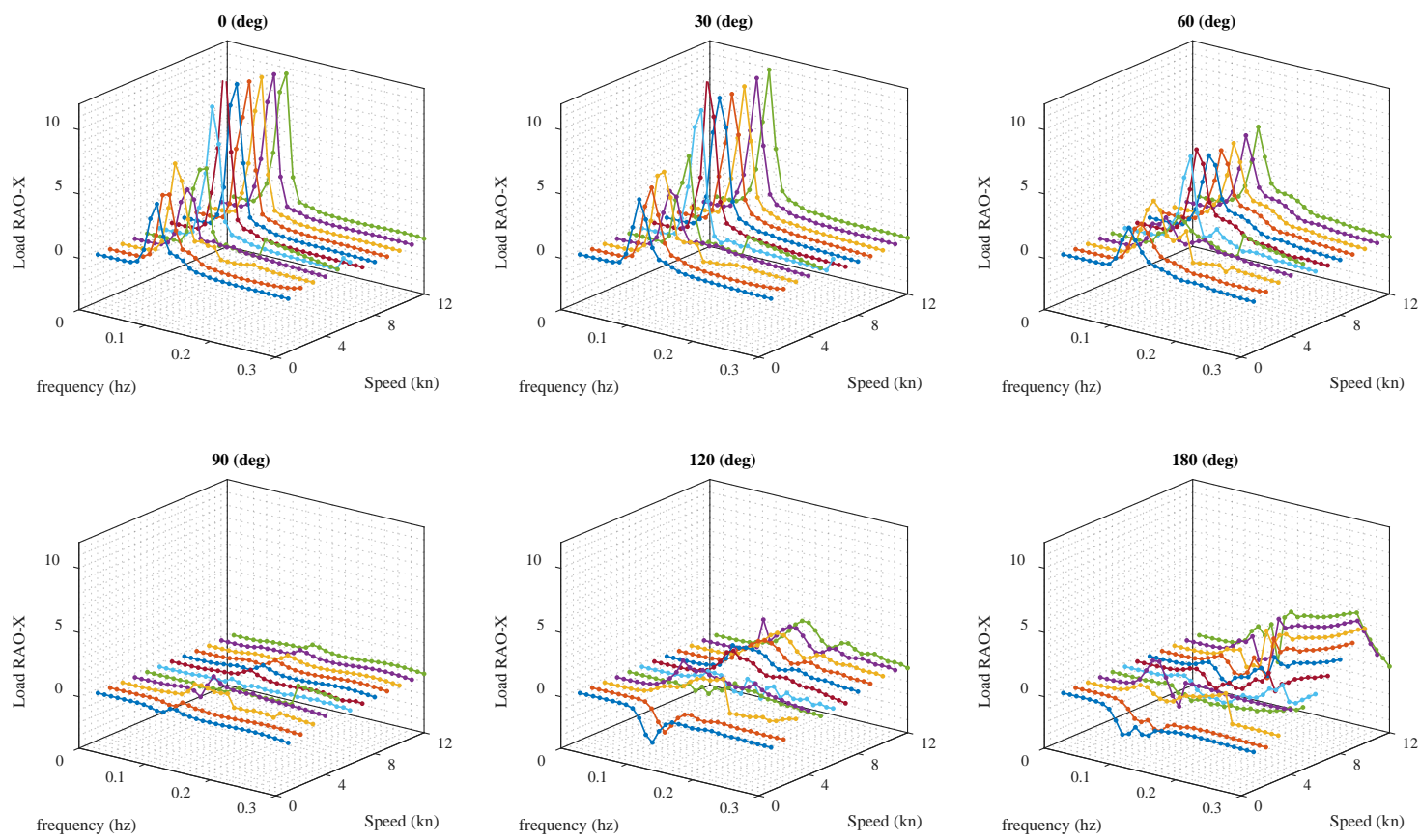

Figure 21. Wave load RAO (X-direction, second-order).

The hydrodynamic coefficients vary due to different combinations of ship speed, wave frequency and wave encounter angle. However, the second-order drift force coefficients appear to have poor stability under the condition of a following sea, which needs further research. The IRFs can be computed in advance of simulations to save the time cost. Parts of the IRF $\left(\mathrm{K}_{22}\right)$ are calculated based on Equation (11) and shown in Figure 22. The contribution of first-order wave load to ship motion can be computed based on the IRFs and linear convolution in time-domain simulation. 

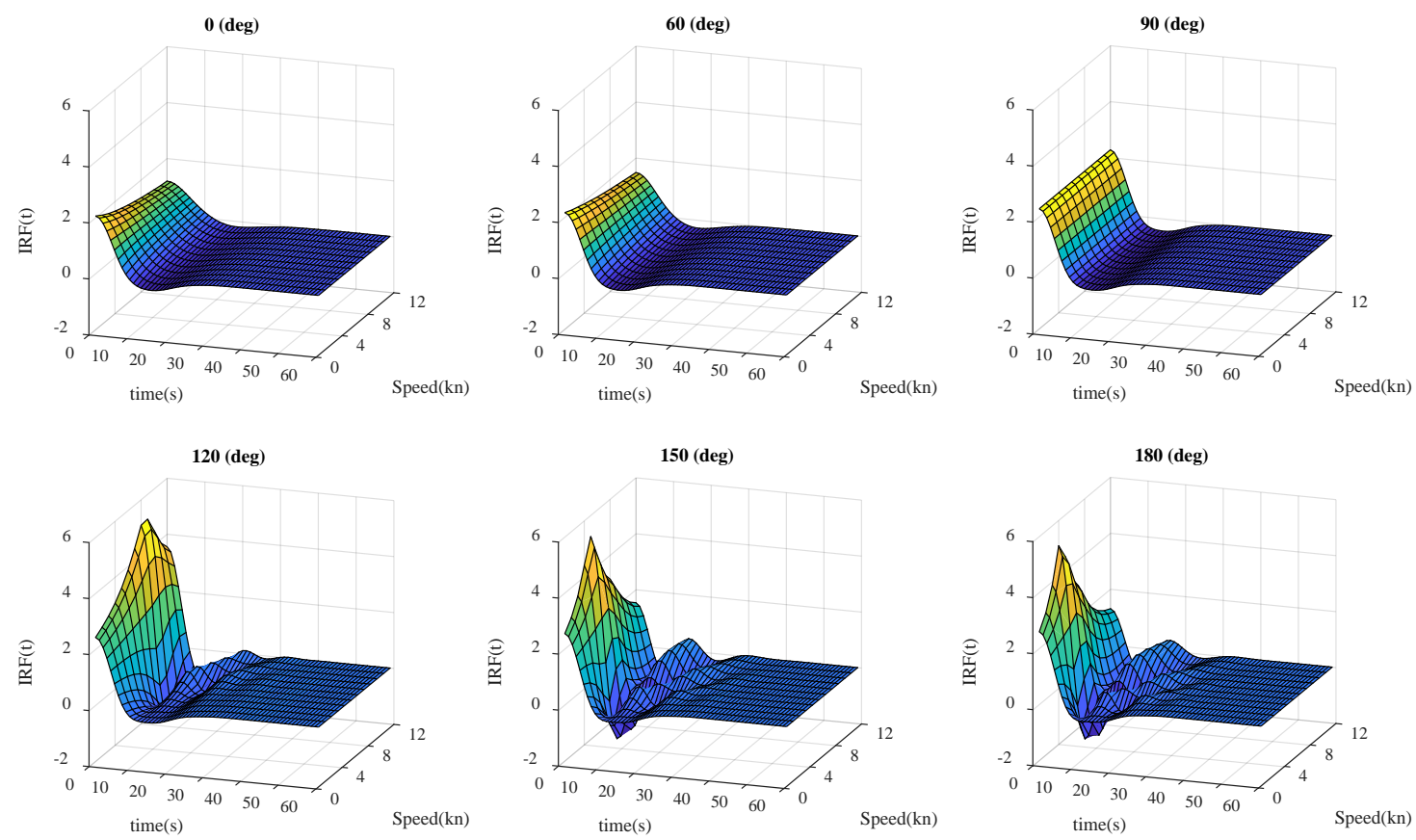

Figure 22. Impulse response functions.

\section{Conclusions}

In this paper, motivated by 3D printing technology, a fast and accurate dense body-plan generation method based on the stereolithographic model is developed. Not only the longitudinal but the transverse and vertical sections can be produced. The number of sections is fully customized to meet the requirement of different calculations. Moreover, the model under arbitrary rotation is also covered in the present method, which could contribute to computing the instantaneous wetted surface area in the strip method. A section redistribution algorithm is purposed for post-processing the non-uniform distribution features inherited from the triangular facets. The redistributed results indicate that the non-uniformity is eliminated in each section based on the purposed algorithm. Two cases are provided to validate the produced data. Firstly, the hull volumes calculated by using the created body plan are compared with the published value. Note that the KVLCC2 model has 24,586 facets, and the relative error of the hull volume is $0.003 \%$ under 500 slices. Secondly, the calculated WSAs are compared with the existing methods. The calculated WSAs based on the produced body plan are highly consistent with the published value at 200 slices. Consequently, the dense body plan is accurate and adaptive for such calculations. Furthermore, time costs under different slices are presented. The slicing operation of the three models is less than $1 \mathrm{~s}$ under 200 slices, which implies the applied potential of the method in time-domain strip theory due to its computational efficiency. A ship hydrodynamic coefficients database is constructed based on the produced data and 2D strip method. The first-order wave memory effect can be computed by Cummins equations based on the interpolation of IRFs. The second-order wave drift effect in the time-domain can be calculated based on the interpolation of drift force coefficients in the database. It is necessary to emphasize that the present method turned the time-consuming task of generating a body plan manually into building the 3D model of a ship hull, and the latter is only a one-time task. Accordingly, the present hydrodynamic database is convenient for simulating the ship maneuvering motion in a seaway. This paper only used the body-plan generation method. Sufficient validation of time-domain simulation should be done in the next step. However, it is reasonable to believe that the method could provide the high-quality data fundamental for strip theory to perform maneuvering simulations in waves. 
Author Contributions: Conceptualization, Q.J.; methodology, Q.J. and H.S.; validation, Q.J.; writing-original draft preparation, Q.J.; writing-review and editing, Q.J. and H.S.; funding acquisition, H.S. and Y.Y. All authors have read and agreed to the published version of the manuscript.

Funding: This research was funded by the project of Intelligent Ship Testing and Verification, 2018/473, China and the Maneuvering Simulation of Yunnan Inland Shipping Ships (No. 851333) and the Fundamental Research Funds for the Central Universities (No. 3132019011) and the Natural Science Foundation Guidance Project of Liaoning Province (no. 2019-ZD-0152) and the Educational Reform of Dalian Maritime University (2018Y08).

Acknowledgments: The authors wish to acknowledge the data support given by Chen and Sasa.

Conflicts of Interest: The authors declare no conflict of interest.

\section{References}

1. Sprenger, F.; Maron, A.; Delefortrie, G.; van Zwijnsvoorde, T.; Cura-Hochbaum, A.; Lengwinat, A.; Papanikolaou, A. Experimental Studies on Seakeeping and Maneuverability of Ships in Adverse Weather Conditions. J. Sh. Res. 2017, 61, 131-152. [CrossRef]

2. Bell, R.; Kirtman, B. Extreme Environmental Forcing on the Container Ship SS El Faro. J. Oper. Oceanogr. 2019, 1-16. Available online: https://www.tandfonline.com/doi/pdf/10.1080/1755876X.2019.1684136?needAccess= true (accessed on 1 July 2018). [CrossRef]

3. Aung, M.Z.; Umeda, N. Manoeuvring Simulations in Adverse Weather Conditions with the Effects of Propeller and Rudder Emergence Taken into Account. Ocean Eng. 2020, 197, 106857. [CrossRef]

4. Xu, J.; Zhao, J.; Zhang, L.; Li, X. Safety Assessment of Navigation Based on Ship Handing Simulator. In Proceedings of the 2019 5th International Conference on Transportation Information and Safety (ICTIS), Liverpool, UK, 14-17 July 2019; pp. 92-98. [CrossRef]

5. Zhang, X.; Xiong, W.; Xiang, X.; Wang, Z. Real-Time Simulation of a Rescue Ship Maneuvering in Short-Crested Irregular Waves. IEEE Access 2019, 7, 133936-133950. [CrossRef]

6. Benedict, K.; Kirchhoff, M.; Gluch, M.; Fischer, S.; Schaub, M.; Baldauf, M. Simulation-augmented methods for safe and efficient manoeuvres in harbour areas. TransNav Int. J. Mar. Navig. Saf. Sea Transp. 2016, 10. [CrossRef]

7. Wang, L.; Wu, Q.; Liu, J.; Li, S.; Negenborn, R.R. State-of-the-Art Research on Motion Control of Maritime Autonomous Surface Ships. J. Mar. Sci. Eng. 2019, 7, 438. [CrossRef]

8. Bailey, P.A.; Hudson, D.A.; Price, W.G.; Temarel, P. Time Simulation of Manoeuvring and Seakeeping Assessments Using a Unified Mathematical Model. Trans. R. Inst. Nav. Arch. 2002, 144, 27-48.

9. Fossen, T.I. A Nonlinear Unified State-Space Model for Ship Maneuvering and Control in a Seaway. Int. J. Bifurc. Chaos 2005, 15, 2717-2746. [CrossRef]

10. Fang, M.-C.; Luo, J.-H.; Lee, M.-L. A Nonlinear Mathematical Model for Ship Turning Circle Simulation in Waves. J. Sh. Res. 2005, 49, 69-79.

11. Skejic, R.; Faltinsen, O.M. A Unified Seakeeping and Maneuvering Analysis of Ships in Regular Waves. J. Mar. Sci. Technol. 2008, 13, 371-394. [CrossRef]

12. Cummins, W. The impulse response function and ship motions. Schiffstechnik 1962, 9, 101-109.

13. Ogilvie, T.F. Recent Progress toward the Understanding and Prediction of Ship Motions. In Proceedings of the 5th symposium on naval hydrodynamics, Bergen, Norway, 10-12 September 1964; Volume 1, pp. 2-5.

14. The Manoeuvring Committee, Final Report and Recommendations to the 27th ITTC. In Proceedings of the 27th International Towing Tank Conference, Copenhagen, Denmark, 31 August-5 September 2014; Volume 1, pp. 1-67.

15. Zhang, W.; Zou, Z.-J.; Deng, D.-H. A Study on Prediction of Ship Maneuvering in Regular Waves. Ocean Eng. 2017, 137, 367-381. [CrossRef]

16. Chillcce, G.; el Moctar, O. A numerical method for manoeuvring simulation in regular waves. Ocean Eng. 2018, 170, 434-444. [CrossRef]

17. Mei, T.; Liu, Y.; Tello Ruiz, M.; Vantorre, M.; Lataire, E.; Chen, C.; Zou, Z. Hybrid Method for Predicting Ship Manoeuvrability in Regular Waves. In Proceedings of the OMAE2019, Glasgow, Scotland, UK, 9-14 June 2019; Volume 7. [CrossRef]

18. Wicaksono, A.; Kashiwagi, M. Wave-induced Steady Forces and Yaw Moment of a Ship Advancing in Oblique Waves. J. Mar. Sci. Technol. 2018, 23, 767-781. [CrossRef] 
19. Subramanian, R.; Beck, R.F. An Improved Body-Exact Method to Predict the Maneuvering of Ships in a Seaway. In Proceedings of the OMAE2019, Glasgow, Scotland, UK, 9-14 June 2019; Volume 9. [CrossRef]

20. Yasukawa, H.; Hirata, N.; Matsumoto, A.; Kuroiwa, R.; Mizokami, S. Evaluations of Wave-Induced Steady Forces and Turning Motion of a Full Hull Ship in Waves. J. Mar. Sci. Technol. 2019, 24, 1-15. [CrossRef]

21. Wicaksono, A.; Kashiwagi, M. Efficient Coupling of Slender Ship Theory and Modular Maneuvering Model to Estimate the Ship Turning Motion in Waves. In Proceedings of the ISOPE-I-19-110, International Society of Offshore and Polar Engineers, Honolulu, HI, USA, 16-21 June 2019; p. 8.

22. Jiao, J.; Sun, S.; Li, J.; Adenya, C.A.; Ren, H.; Chen, C.; Wang, D. A Comprehensive Study on the Seakeeping Performance of High Speed Hybrid Ships by 2.5D Theoretical Calculation and Different Scaled Model Experiments. Ocean Eng. 2018, 160, 197-223. [CrossRef]

23. Zhao, C.; Ma, M. A Hybrid 2.5-Dimensional High-Speed Strip Theory Method and Its Application to Apply Pressure Loads to 3-Dimensional Full Ship Finite Element Models. J. Sh. Prod. Des. 2016, 32, $216-225$. [CrossRef]

24. Ma, S.; Duan, W.-Y.; Song, J.-Z. An Efficient Numerical Method for Solving '2.5D' Ship Seakeeping Problem. Ocean Eng. 2005, 32, 937-960. [CrossRef]

25. Gourlay, T.; von Graefe, A.; Shigunov, V.; Lataire, E. Comparison of AQWA, GL Rankine, MOSES, OCTOPUS, PDStrip and WAMIT With Model Test Results for Cargo Ship Wave-Induced Motions in Shallow Water. In Proceedings of the OMAE2015, Newfoundland, Canada, 31 May-5 June 2015; Volume 11. [CrossRef]

26. Park, D.-M.; Kim, Y.; Seo, M.-G.; Lee, J. Study on Added Resistance of a Tanker in Head Waves at Different Drafts. Ocean Eng. 2016, 111, 569-581. [CrossRef]

27. Guo, B.; Ruth, E.; Austefjord, H.; Bitner-Gregersen, E.M.; Gramstad, O. Study on Ship Manoeuvering in Adverse Sea State. In Proceedings of the OMAE2017, Trondheim, Norway, 25-30 June 2017; Volume 3. [CrossRef]

28. Kristiansen, E.; Hjulstad, Å.; Egeland, O. State-Space Representation of Radiation Forces in Time-Domain Vessel Models. Ocean Eng. 2005, 32, 2195-2216. [CrossRef]

29. Donatini, L.; Vantorre, M.; Verwilligen, J.; Delefortrie, G. Description of Hydro/Meteo Data in Ship Manoeuvring Simulators: A Survey on the State of the Art. Ocean Eng. 2019, 189, 106344. [CrossRef]

30. Oanta, E.; Hreniuc, V.C.; Grosu, C.D. Effective Method Used to Create the Analytical Models of Large Sets of Curves - Application for the Ship Hull Body Plan. IOP Conf. Ser. Mater. Sci. Eng. 2018, 400, 042043. [CrossRef]

31. Mohammed, J.S. Applications of 3D printing technologies in oceanography. Methods Oceanogr. 2016, 17, 97-117. [CrossRef]

32. Kloske, R.; Josten, M.; Carstensen, B. Resistance tests with 3D printed models in the early ship design stage of high speed vessels. In Sustainable Development and Innovations in Marine Technologies, Proceedings of the 18th International Congress of the Maritme Association of the Mediterranean (IMAM 2019), Varna, Bulgaria, 9-11 September 2019; CRC Press: Boca Raton, FL, USA, 2019; p. 150.

33. Liu, C.; Zhang, X.; Sun, X.; Yin, Y. Improved Draft Survey Method Based on Densified Table of Offsets. J. Traffic Transp. Eng. 2014, 14, 58-64.

34. Shen, H.; Liu, C.; Yin, Y.; Sun, X. Automatic Stowage of Bulk Carrier Based on Ship Floating-State Control. J. Sh. Res. 2019, in press. [CrossRef]

35. Most Used 3D Printing Technologies 2017-2018. Available online: https://www.statista.com/statistics/560304/ worldwide-survey-3d-printing-top-technologies/ (accessed on 1 July 2018).

36. Stern, F.; Agdrup, K.; Kim, S.Y.; Hochbaum, A.C.; Rhee, K.P.; Quadvlieg, F.; Perdon, P.; Hino, T.; Broglia, R.; Gorski, J. Experience from SIMMAN 2008The First Workshop on Verification and Validation of Ship Maneuvering Simulation Methods. J. Sh. Res. 2011, 55, 135-147.

37. Wang, C.-S.; Chang, T.-R. Re-Triangulation in STL Meshes for Rapid Prototyping and Manufacture. Int. J. Adv. Manuf. Technol. 2008, 37, 770-781. [CrossRef]

38. Zheng, H.; Cong, M.; Liu, D.; Dong, H.; Liu, Y. Optimization of STL Model and Layer Shape for Laser Cladding Forming. Int. J. Adv. Manuf. Technol. 2019, 100, 599-608. [CrossRef]

39. Ledalla, S.R.K.; Tirupathi, B.; Sriram, V. Performance Evaluation of Various STL File Mesh Refining Algorithms Applied for FDM-RP Process. J. Inst. Eng. India Ser. C 2018, 99, 339-346. [CrossRef]

40. Shaher Sabit, A. Regression Analysis of the Resistance Results of the BSRA Series. Int. Shipbuild. Progress 1971, 18, 3-17. [CrossRef] 
41. Molland, A.F.; Turnock, S.R.; Hudson, D.A. Ship Resistance and Propulsion: Practical Estimation of Ship Propulsive Power, 2nd ed.; Cambridge University Press: Cambridge, UK, 2017; ISBN 978-1-107-14206-0.

42. Holtrop, J.; Mennen, G. An Approximate Power Prediction Method. Int. Shipbuild. Progress 1982, $29,166-170$. [CrossRef]

43. Schneekluth, H.; Bertram, V. Ship Design for Efficiency and Economy; Butterworth-Heinemann: Oxford, UK, 1998; Volume 218, ISBN 978-0-7506-4133-3.

(C) 2020 by the authors. Licensee MDPI, Basel, Switzerland. This article is an open access article distributed under the terms and conditions of the Creative Commons Attribution (CC BY) license (http://creativecommons.org/licenses/by/4.0/). 